\title{
Ability of moisture absorbing substrate to conserve percolating water
}

\author{
Ampitiyawatta, A.D. \& Weerasuriya W. M. I \\ Department of Export Agriculture, Faculty of Agricultural Sciences, Sabaragamuwa University of Sri Lanka
}

\begin{abstract}
Though water is the most abundant natural resource on the earth, in most occasions, it is limited to agriculture especially in dry spells and dry regions. This is aggravated by higher losses from evaporation as well as percolation. If a method adopts to trap percolating water that would be one of the appropriate alternatives which helps to survive plants during dry climates and increase the water use efficiency. Therefore, the present study aims to identify the possibility of reducing percolation by using moisture absorbing substrate beneath the root zone. Three moisture absorbing substrates i.e sponge, biochar and sawdust were used as treatments and a control experiment was conducted without any water absorbing material. Treatmentswere arranged as Complete Randomized Design with three replicates. Treatments were buried at $20 \mathrm{~cm}$ depth as $5 \mathrm{~cm}$ layer separated by high gauge polythene. In a $90 \mathrm{~cm} \times 180 \mathrm{~cm}$ plot, 12 chilli (Capsicum annuum) plants were planted as two plants per hole.All recommended agronomic practices were carried out.Soil moisture content was maintained above $50 \%$ allowable depletion level by measuring it dailythroughout the experiment, supplying the deficiency. Days to $50 \%$ flowering, plant height at $50 \%$ flowering, first harvesting yield, plant biomass and root biomass were measured.There were no significant differences in plant height, days to $\mathbf{5 0 \%}$ flowering, plant biomass or root biomass between treatments. It indicates that there was no any moisture stress among treatments. However, there was a significant difference among the treatments in water usage by the crop throughout the duration. The water usage was significantly lower in sponge compare to other treatments. It means sponge material can conserve water at the rate of $992.59 \mathrm{~m}^{3} / \mathrm{ha}$ without any effect on the yield. Therefore, a substrate can be used to effectively conserve soil moisture by reducing the percolation and sponge is the best among tested treatments.
\end{abstract}

Keywords: moisture absorbent material, substrate, water holding capacity, sponge

\section{INTRODUCTION}

A griculture is one of the main income sources of Sri Lanka which contributes more than $7 \%$ to the national economy. It is highly depending on two major monsoons: South West monsoon (SWM) from June to September and North East Monsoon (NEM) from December to February; and two inter-monsoons: First Inter-Monsoon (FIM) from March to May and Second Inter-Monsoon (SIM) from October to November (Suppiah 1996). Accordingly, a distinct bi-modal rainfall pattern could be identified, leading to two cropping seasons which are named as Yala (minor) and Maha (major) season. However, the adverse weather conditions observed during recent past caused significant crop losses.The annual report (2016) of Central bank of Sri Lankastated that adverse weather conditions such as prolonged droughts and floods negatively affected to agricultural performances. Therefore, having ample water is essential for the successfulness of agriculture. Rainfall is the major source of water for conventional agriculture. Monsoon rainfalls accounts for the major share of the annual rainfalls whereasconventional and cyclonicrainfalls also contributeconsiderable amount to the annual total. Based on total annual rainfall and its distribution, Sri Lanka is divided into three main climatic zones namely Dry $(<1750 \mathrm{~mm})$, Intermediate $(1750-2500 \mathrm{~mm})$ and Wet (>2500 mm) (Punyawardena and Kulasiri 1996). Dry zone is the main agricultural region out of those which accounts for $60 \%$ of total land areawith fertile soil, hence there is a high potential for the cultivation of arable crops. Lack of rainfall and high evaporation caused by elevated temperature are major constraints achieving higher yields (Punyawardena and Kulasiri, 1996). Further, recent findings on climate change (De Silva, 2006) envisaged that decreases of rainfall and increase of temperature leads to potential soil moisture deficits which will create higher irrigation demand. Therefore, adoption measures such as changing crops, varieties, timing of plating and water saving methods are important for continuous cultivation in dry zone (De Silva, 2006).

As soil is the main medium of cultivation of crops, soil health is important for determining the yield of crops. Healthiness refers to a collection of physical, chemical and biological properties of soil. Soil water has a greater influence on all of the above-mentioned properties. The soil acts as the major reservoir for water and store moisture during rainfall or irrigation and supplies to plants continuously. The water holding capacity of a soil is an inherent character and that could be enhanced by various management practices such as loosing, incorporating organic manure etc. The moisture storage capacity of a soil provides a buffer which determines a plant's capacity to withstand during dry spells. When the soil is subjected to irrigation or rainfall, a part of infiltrated water drains through the soil profile due the gravity and that is not available for plant. Other part is stored between soil particles as capillary or hygroscopic water and only the capillary water is available for plants. If the draining or percolating water due to gravity is stored by using natural or artificial substrate underneath the root zone, that water could be utilized by the plant during dry spells. It may facilitate to safeguard the plant during the harsh climate and contribute to produce sustainable yields. Therefore, the present study attempted to identify the possibility of reducing percolation by using moisture 
absorbing substrate beneath the root zone.

\section{MATERIALS AND METHODS}

\section{Experimental Site}

A field experiment was conducted at the Faculty farm, Faculty Agricultural Sciences, Sabaragamuwa University of Sri Lanka, Belihuloya during the Yala (Minor) agricultural season in 2017. The site belongs to Mid Country Intermediate Zone (IM2b) according to agro climatological zoning map of the country(Punyawardena, 2008).The annual average rainfall is about $1250 \mathrm{~mm}$ and annual average temperature is $25^{\circ} \mathrm{C}$. The soil type of the site is Alfisol.

\section{Experimental design and treatments}

Complete Randomized Design was used with three treatments i.e Sponge (T1) Biochar (T2), and Sawdust (T3) as water absorbing substrates and a control (T4) experiment was conducted without any water absorbing substrate. Treatments were replicated three times. A plot size was $90 \mathrm{~cm} \times 180 \mathrm{~cm}$ with 6 planting holes and two Chilli (Capsicum annuum) plants were planted in one-hole accounting 12 plants per plot. The moisture content of the soil was measured daily and it was maintained above the $50 \%$ of allowable depletion level throughout the experimental period by supplying the deficiency. During land preparation, all weeds were removed by using a mammoty and soil was pulverized. By removing soil up to $25 \mathrm{~cm}$ depth, $5 \mathrm{~cm}$ thick layer of treatment substrates were filled into plots and then top soil was layered above the treatments up to the surface level. Plots were separated by black polythene. All recommended agronomic practices were carried out after planting chilli plants.

\section{Measurements}

\section{A. Soil}

Filed capacity, permeant wilting point and bulk density of the soil was estimated according to Singh (2001). Soil texture was determined by the Hydrometer method with ISSS system (Government of Maharashtra, 2009). In-situ soil moisture content was measured by using a portable soil moisture meter "Aquaterr Digital Soil Moisture Meter - model M- 300". Net irrigation requirement of the crop was estimated by following equation using above soil parameters and plants were irrigated with that.

$$
\mathrm{NIR}=\frac{(\mathrm{FC}-\mathrm{MCbi})}{100} \times \mathrm{BD} \times \mathrm{h}
$$

NIR - Net Irrigation Requirement of the crop (cm)

FC - Field capacity of the soil (\%)

MCbi - Moisture content of the soil before irrigation (\%)

BD - Bulk density of the soil $\left(\mathrm{g} / \mathrm{cm}^{3}\right)$

$\mathrm{h}$ - Root zone depth (cm)

\section{B. Plant}

Height $(\mathrm{cm})$ of each plant was measured with a meter ruler at three times i.e at planting, 50\% flowering and $1^{\text {st }}$ harvesting. Time (days) taken to $50 \%$ flowering of plants was observed in each plot. Fully matured unripe pods were taken as the yield (g). Two plants were uprooted from each plot and obtained the plant fresh biomass (g) androot and above ground biomass (g) as dry weight three months after planting.

\section{Metrological data}

Daily rainfall and evaporation were measured using a manually operated rain gauge and temporary installed evaporation pan, respectively.

\section{RESULTS AND DISCUSSION}

All measured biometric parameters of the crop i.e number of days taken to $50 \%$ of flowering, average plant height at three growing stages, plant fresh weight, above ground dry weight, root dry weight and yield are not significantly different among various substrates and with the control. This implies that plant growth under any substrate is very similar without facing any stress condition. Plants under any substrate showed optimum growth conditions comparable to the control. Total fresh weight, above ground and root biomass are also more similar the control.It is an evident that plants have not been faced to any stress condition by showing comparable results to achieve $50 \%$ flowering. Though there are slight changes of the yield among different treatments those are not significant (Figure 1). It indicates that all soil substrates perform equally and finally produce the same yield. According to Puértolaset al., (2017), maximum yield of green chilli can be obtained by supplying adequate amount of water during the growing period without any moisture stress condition. Therefore, it is evident that all substrates are able to manage the optimum moisture content that is field capacity during the most of the growth period.

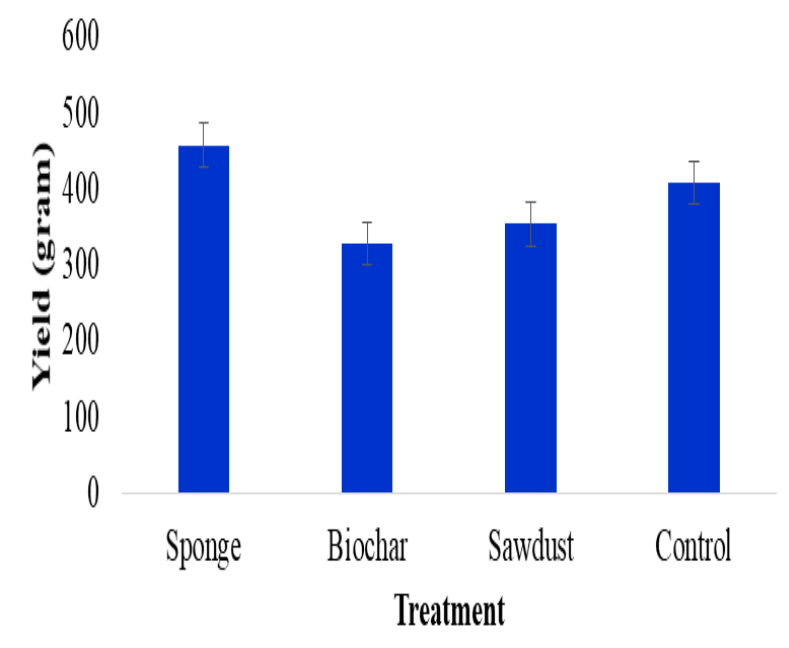

Fig. 1 Yield under various substrates 
Figure 2 shows the Net Irrigation requirement of each plot. Accordingly, water requirement for crop under the substrate of sponge significantly differ $(\mathrm{p}<0.05)$ from the saw dust and the control. Though the water requirement for the crop under sponge treatment is lower than the biochar, the difference is not statistically significant.

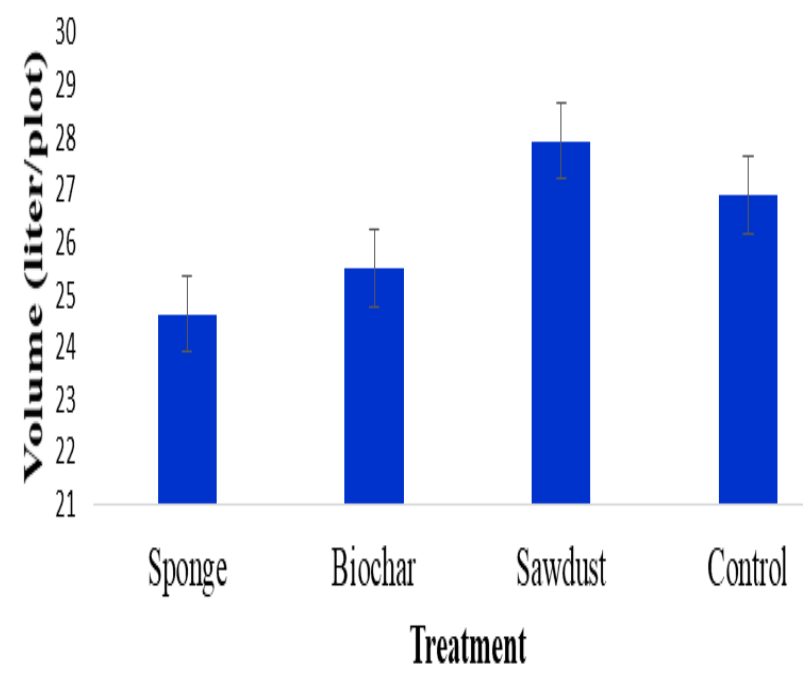

Fig. 2 Water requirement for various treatments

The water usage by the crop under sponge treatment was the lowest which conserved $992 \mathrm{~m}^{3} /$ ha and it was $10 \%$ reduction than the control. The highest water requirement was recorded for crop under saw dust treatment. That was higher than the control treatment. Therefore, maximum water use efficiency was shown by the crop under sponge treatment.

\section{CONCLUSION}

A buried moisture absorbing substrate can be effectively used to reduce the percolation of irrigated water and thereby conserve the soil moisture. The best material to reduce the percolation is sponge among the tested materials. The reduction of percolation was $10 \%$ and that was achieved without any affect to the plant growth and to the yield. The tested method may beneficial for dry and arid regions where irrigation water is scanty and in soils where percolation is high.

\section{REFERENCES}

[1] Central Bank of Sri Lanka (2016), Annual Report. p. 02

[2] De Silva \&ShanthiC. (2016). Impacts of climate change on water resources in Sri Lanka. 32 ${ }^{\text {nd }}$ WEDC International Conference on Sustainable Development of water resources, water supply and environmental sanitation, 13-17 $7^{\text {th }}$ November 2006, 502-508

[3] Puértolas, J., Larsen, E., Davies, W. \& Dodd, I. (2017). Applying 'drought' to potted plants by maintaining suboptimal soil moisture improves plant water relations. Journal of Experimental Botany, 68(9), 2413-2424

[4] Punyawardena, B.V.R. (2008). Precipitation of Sri Lanka and agro-ecological regions (in Sinhala). Agriculture Press, Sri Lanka

[5] Punyawardena, B.V.R. \&Kulasiri, D. (1996). On development and comparative study of two Markov models of rainfall in the dry zone of Sri Lanka. Research Report 96/11, Lincoln University

[6] Singh, R. (2001). Soil Physical Analysis. 2 ${ }^{\text {nd }}$ ed. New Delhi: Kalyani Publisher, 119

[7] Suppiah, R. (1996). Spatial and temporal variations in the relationships between the Southern Oscillation phenomenon and the rainfall of Sri Lanka. International Journal of Climatology,16, 1391-1407. 